\title{
Study on Power Test and Assessment of the Missile Warhead
}

\author{
Xiujuan Gao, Lin Wang, You Zhao \& Xiaohui Li \\ Baicheng Ordnance Test Center of China, Baicheng, Jilin, China
}

\begin{abstract}
In order to assess tactical and technical index of a certain type of missile warhead, calculated warhead muzzle velocity and damage capacity for using of theoretical analysis. Combined with the results, design the new target emplaced scheme. To the particularity of warhead structure and measured data, combined with fragments scattering theory, made a valid assessment of the warhead flying characteristics with fragments scattering theory. The results show that the new target emplaced structures can be used for recording data of similar warhead and fragments scattered segments assessment results can be used for reacting scattering properties of such warheads objectively.
\end{abstract}

KEYWORD: Missile warhead; fragment scattering properties; assessment; theoretical analysis

\section{INTRODUCTION}

A conventional medium range ballistic missiles, ballistic speed, strong penetration ability, powerful warhead. Its operational target is mainly for the enemy ground personnel, parked aircraft, airport runway, ground light armored vehicles, etc. For the general tactical missile warhead, the test and evaluation methods, mainly the implementation of GJB5232 "the warhead missile warhead shooting range test method "and GJB6390 "the surface destruction missile warhead static explosion power test method" and other standards. But for the tactical and technical indexes of the missile warhead proposed, test according to the syllabus, the target range laying method for traditional, not effective on the tested. And because of the particularity of the warhead structure, fragmentation characteristics of the classic, can not accurately describe flying fragments. In this paper through theoretical analysis, combined with tactical and technical index, designed the layout scheme of the target range, and combined with the classical fragment dispersion theory, assessment of this type of warhead fragment scattering characteristics.

\section{TARGET DESIGN AND VERIFICATION}

\subsection{Test requirements}

The warhead for platform structure which is different from the general structure of warhead. Testing requirements of the fragment velocity of testing the axial distribution, fragment scattering characteristics, prefabricated fragment damage ability and so on, combined with the warhead of tactical and technical index, range layout scheme as shown in Figure 1.

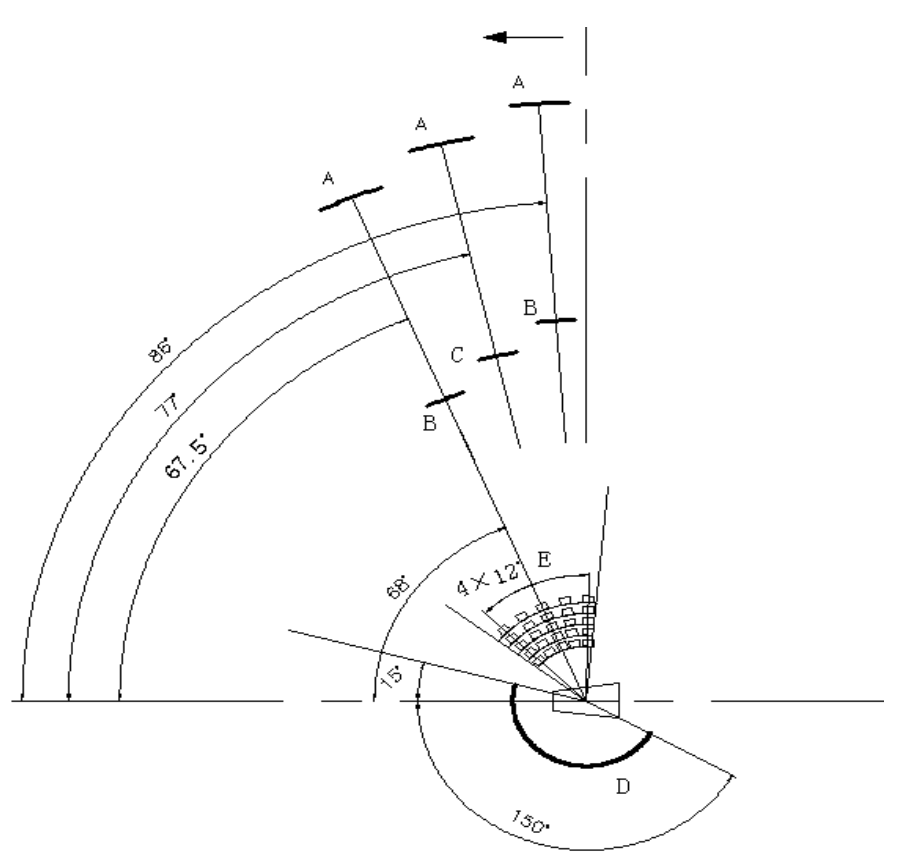

Figure 1. Schematic diagram of the static blasting station of the warhead 


\subsection{Target design}

Traditional damage test target for steel target structure, as shown in Figure 2, for the general damage test with a schematic diagram, table 1 is the national standard target board specifications.

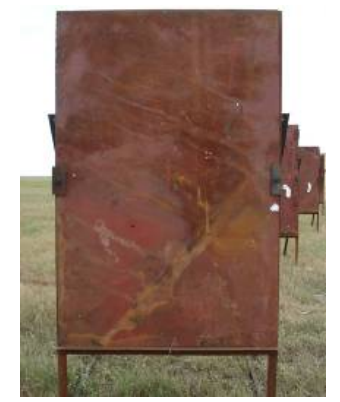

Figure 2. Traditional target structure diagram

Table 1. GB target board specifications

\begin{tabular}{lll}
\hline target plate material & $\begin{array}{l}\text { National Stand- } \\
\text { ard Specification }\end{array}$ & $\begin{array}{l}\text { National standard } \\
\text { mass }\end{array}$ \\
\hline $\begin{array}{l}\text { Galvanized Sheet } \\
\text { Q235 Plate }\end{array}$ & $\begin{array}{l}1 \mathrm{~m} \times 2 \mathrm{~m} \\
2 \mathrm{~m} \times 1.26 \mathrm{~m}\end{array}$ & $\begin{array}{l}15.6 \mathrm{~kg} \\
78 \mathrm{~kg}\end{array}$ \\
$\begin{array}{l}\text { LY12 aluminum } \\
\text { plate }\end{array}$ & $1.0 \mathrm{~m} \times 1.2 \mathrm{~m}$ & $35 \mathrm{~kg}$ \\
\hline
\end{tabular}

For this type of warhead equivalent target requirements and the main killer element analysis, combined with the national standard target specifications, traditional steel structure is not good for testing, need to establish a new way of target cloth and a fixing structure. The warhead is preformed fragment warhead, no larger fragments, so to close the destruction of the target structure, mainly is overpressure of shock wave, damage to the distant target structure, mainly throughout the fragment. Therefore, the proposed use of wood to target the overall construction, rather than the traditional single steel target splicing.

\subsection{Theoretical analysis}

The warhead TNT equivalent to 650kg, according to classical shock wave overpressure experience formula, the shock wave with distance attenuation curve as shown in Figure 3. According to the gurney formula, the prefabricated spherical fragment velocity with distance attenuation curve as shown in Figure 3 (SUI shu-yuan et al, 2000) (WANG Ru-ce et al, 1993) (ZHAO Wen-xuan et al, 1989).

$$
\Delta P_{m}=0.082\left(\frac{\sqrt[3]{\omega_{T N T}}}{R}\right)+0.26\left(\frac{\sqrt[3]{\omega_{T N T}}}{R}\right)^{2}+0.69\left(\frac{\sqrt[3]{\omega_{T N T}}}{R}\right)^{3}
$$

As in Eq. (1): - shock wave front on the super pressure, MPa; -TNT equivalent, kg. In the near ground explosion, due to the reflection of the ground effect, a considerable amount of desirable 1.8; - distance from the explosion center distance, $\mathrm{M}$.

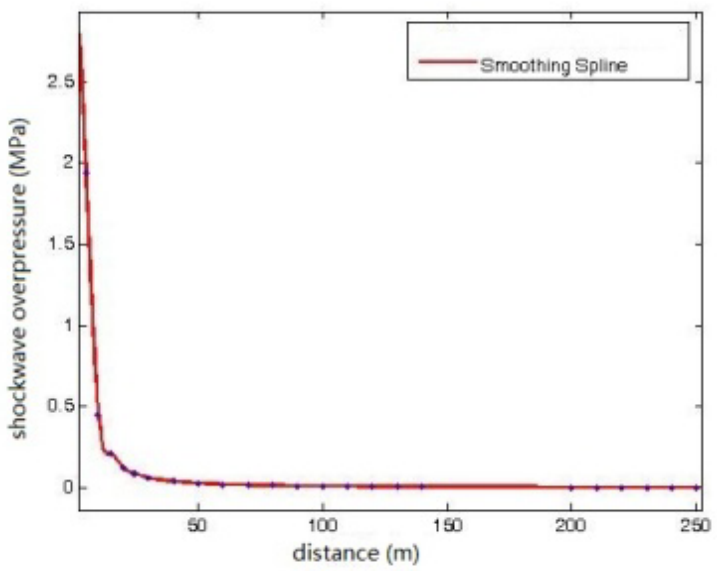

Figure 3. Attenuation curve of shock wave

$V_{0}=D \sqrt{\frac{\beta}{5(2+\beta)}}$

As in Eq. (2): $\mathrm{v}_{0}$ - initial velocity, $\mathrm{m} / \mathrm{s}$; D- charge detonation velocity, $\mathrm{m} / \mathrm{s} ; \beta$ - charge ratio.

$\alpha=\rho C_{D} \frac{A}{2 m}$

$V_{\mathrm{t}}=V_{0} e^{-\alpha R}$

As in Eq. (3). (4): $\alpha$ - Velocity attenuation coefficient , $\mathrm{m}^{-1} ; \rho$ - Air density, $\mathrm{kg} / \mathrm{m}^{3} ; C_{D}$ - The resistance coefficient of spherical fragments, 0.93; $A$ - Spherical fragments average windward area, $\mathrm{m}^{2}$; $m$ - The quality of prefabricated fragments, kg; $v_{t}{ }^{-}$ Distance $\mathrm{R}$ meters of the heart of the deposit speed, $\mathrm{m} / \mathrm{s} ; R$-Distance from the explosion center, $\mathrm{m}$.

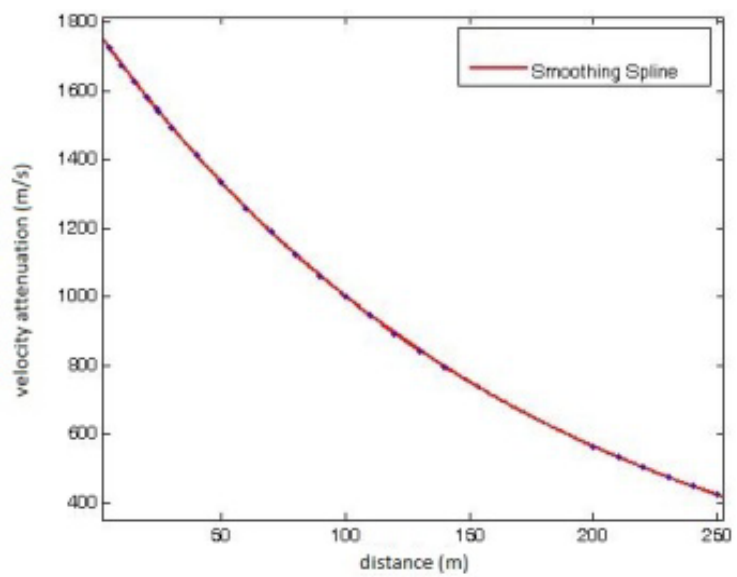

Figure 4. curve of velocity attenuation

From the figure 3 and 4 analysis, we found that the shock wave overpressure value and the survival 
rate of each target point are shown in Table 2. The target of overpressure is far less than the yield strength and shear strength of the target, and the fragment is mainly prefabricated fragment, only on the target plate caused through, not on the target plate caused large area tearing. Because the supporting structure at $24 \mathrm{~m}$ is wooden, may cause the collapse of the target, but the admission does not affect the fragment.

Table 2. The shock wave overpressure and the deposit velocity of each target point

\begin{tabular}{lll}
\hline $\begin{array}{l}\text { Cloth target } \\
\text { distance } \\
(\mathrm{m})\end{array}$ & $\begin{array}{l}\text { Overpressure of } \\
\text { shock wave } \\
(\mathrm{MPa})\end{array}$ & $\begin{array}{l}\text { Fragment velocity } \\
(\mathrm{m} / \mathrm{s})\end{array}$ \\
\hline 24 & 0.09 & 1546.3 \\
120 & 0.0092 & 892.3 \\
130 & 0.0084 & 842.6 \\
140 & 0.0076 & 795.7 \\
200 & 0.005 & 564.3 \\
210 & 0.0047 & 532.9 \\
220 & 0.0045 & 503.2 \\
\hline
\end{tabular}

\subsection{Test verification}

According to the above analysis, the site target construction, as shown in Figure 5, for the site layout. Static explosion found that $1 \mathrm{~mm} 24 \mathrm{~m}$ galvanized plate target the overall collapse, but the galvanized sheet without tearing damage; $120 \mathrm{~m}$ all the targets are not damaged. With the target construction scheme, the project can be completed effectively, and has the following advantages:

(1) Target high accuracy for target scattering characteristics, can be arranged according to the arc. For other kinds of targets, it can ensure the whole target surface is smooth, completely avoid the traditional target to bring the layout error.

(2) The overall intensity is good, for the destruction of the power target, the use of wooden support, can ensure that the overall strength and requirements.

(3) The service is good, with the national standard target, operation service is good, to avoid the operation of Engineering machinery.

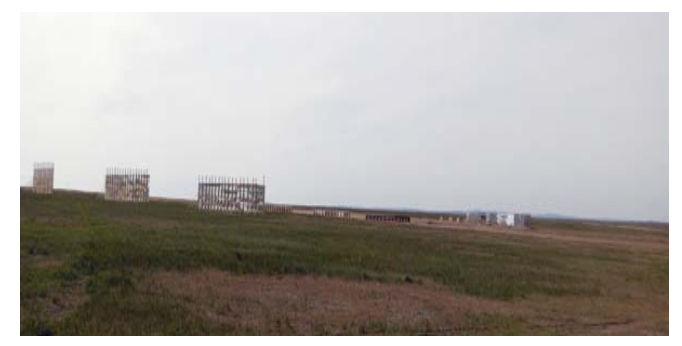

Figure 5. static explosion target construction plans

\section{RESEARCH ON THE EVALUATION METHOD OF WARHEAD DAMAGE}

\subsection{Velocity distribution}

The warhead is big end initiation, according to the classical one end initiation equation (5) can be calculated axial velocity distribution curve, as shown in Figure 6 axis direction of the fragment distribution diagram of calculation, as shown in Figure 7 axis direction of the fragment distribution theoretical curve and the experimental data curve (WANG Lin et al, 2013).

$V_{0 x}=\left(1-e^{-\frac{2.3617 x}{d}}\right)\left(1-0.28806 e^{-\frac{4.603(L-x)}{d}}\right) V_{0}$

As in Eq. (5): $\quad v_{o x}$ - from the large end at $x$ fragment velocity, $\mathrm{m} / \mathrm{s} ; x$ - distance from large end face, $\mathrm{m} ; d$ - warhead diameter, $\mathrm{m} ; L$ - warhead length, $\mathrm{m}$.

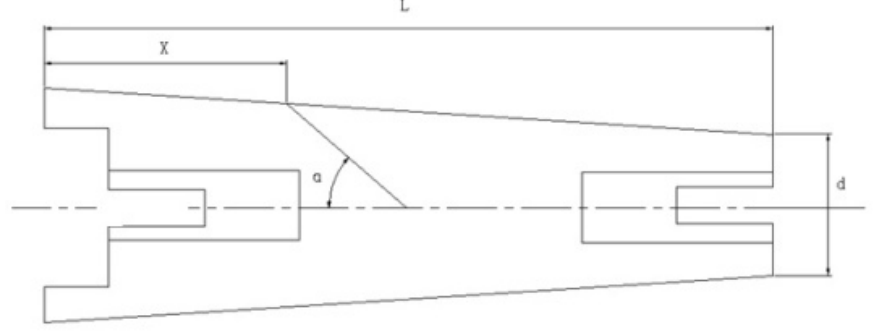

Figure 6 . The figure of the structure of the warhead

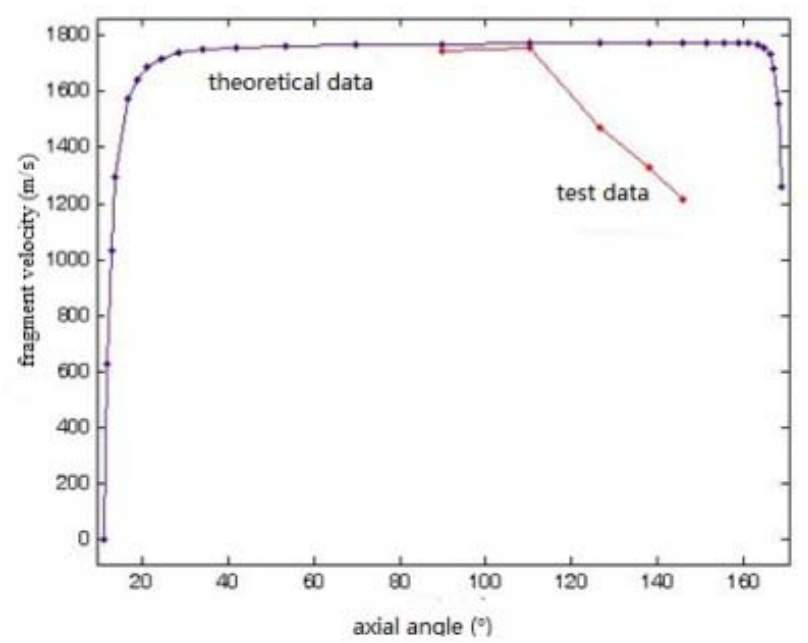

Figure 7. the curve of the axial distribution of fragment velocity

From the curve of Figure 7, the data analysis, the theoretical data and the experimental data agree are not the same. The reason is that the axial one end initiation is derived based on cylindrical structure, and the warhead is a truncated cone type structure, its diameter is change, which led to the in fighting the end face of the speed decreased sharply, in line with the actual situation. 


\subsection{Damage ability}

For the $6 \mathrm{~mm}$ and diameter of $8 \mathrm{~mm}$ Tungsten Ball, for steel and aluminum, fragment of target formation perforation of the kinetic energy should not be less than the target of dynamic deformation work (WANG Feng-ying et al, 2009):

$$
E_{k} \geq K_{1} S_{m} b \sigma_{b}
$$

As in Eq. (6): $K_{1}$ - Ratio coefficient; $S_{m}$ - the area, $\mathrm{m}^{2} ; b$ - Target thickness, $\mathrm{m} ; \sigma_{b}$ - Critical stress of target materials, Pa. According to the results of Table 3, for different target point, the theory can form perforation capability.

\subsection{Scattering characteristics}

As figure 8 and 9 shows, for this type of warhead fragment dispersion characteristics and spatial distribution curve, according to the classical dispersion theory calculation (WANG Lin et al, 2012), at both ends of each of the 5\% corresponds to the angle, the fragment dispersion angle range is 1 to $109^{\circ}$, fragment dispersion angle $108^{\circ}$. But the combination of fragment distribution curve and target board target fragment number, at $20^{\circ}-47^{\circ}$, no target fragment. So, using the classical dispersion theory of tradition, is not valid for this type of warhead fragment evaluation. Can be taken to assess the segmentation method, that is, according to the $0^{\circ}-30^{\circ}, 30^{\circ}-180^{\circ}$ two sections of the analysis. Each interval is calculated according to classical scattering theory. In the range of $0^{\circ}$ to $30^{\circ}$, fragment dispersion angle for 8 degrees, $30^{\circ}$ to $180^{\circ}$ interval in that fragment dispersion angle for $48^{\circ}$, so according to the method to calculate, the fragment dispersion angle for $56^{\circ}$.

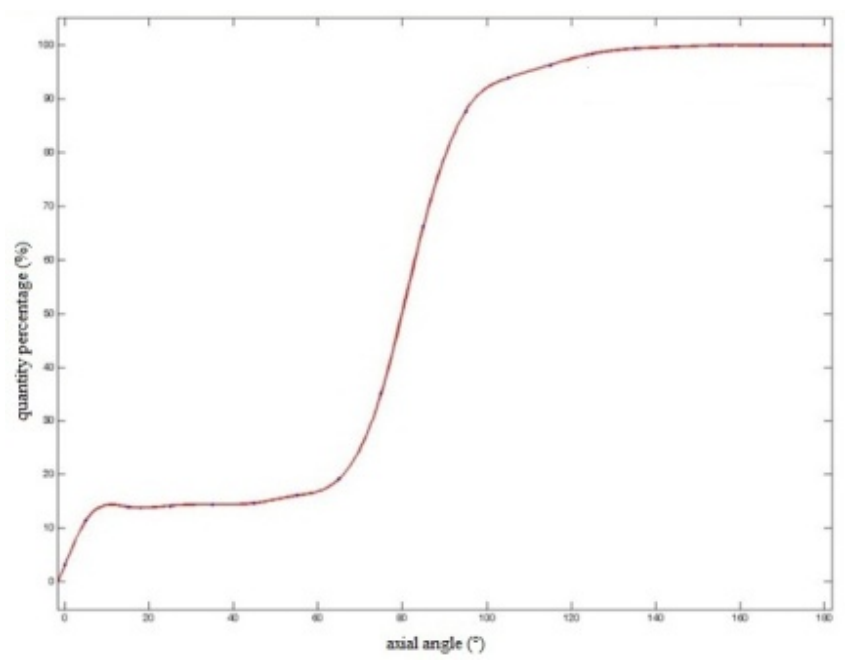

Figure 8. the curve of fragmentation characteristic

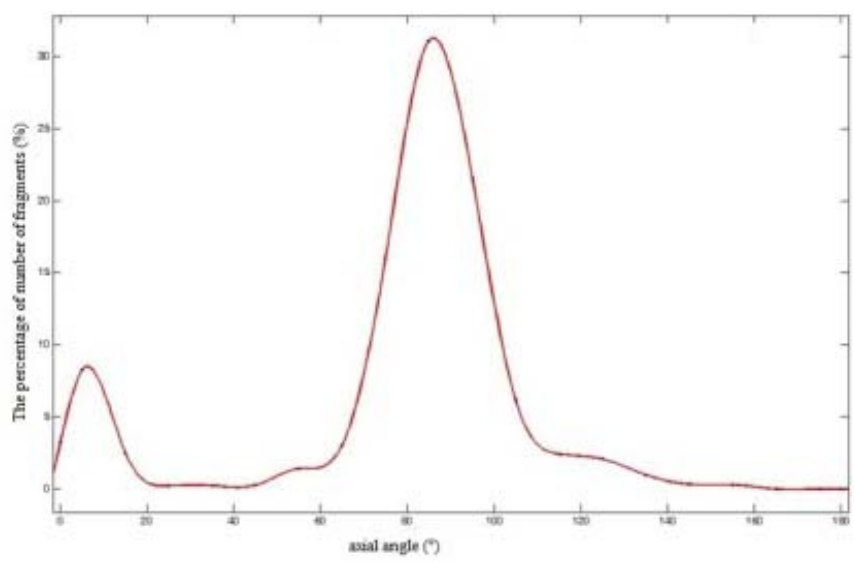

Figure 9. The curve of fragment distribution

\section{CONCLUSIONS}

In this paper, according to the existing problems of a certain type of missile warhead, a new method of target layout is designed in view of the problems existing in the current target. And combined with the test data, the combat effectiveness of the damage was effectively assessed. The results show that due to the warhead shape design reasons, leading to the fragment of the axial velocity and dispersion characteristics of fragment distribution characteristic parameters, and the traditional and classical theories differ, the proposed a piecewise assessment of thought, objective response of this kind of combat damage characteristics.

\section{REFERENCES}

SUI shu-yuan, ect. Terminal effects[M].BeiJing: National Defence Industry Press, 2000.

WANG Feng-ying, ect. Damage theory and technology[M]. BeiJing: BeiJing institute of technology press, 2009.

WANG Lin, ect. Study on the Scatter of High Capacity Head Fragments[J].Journal of projectiles,Rockets,Missiles and guidance. 2012.32(6):68 70.

WANG Lin, ect. The Analysis of Influence of Detonation Mode on Warhead Lithality[J].Journal of projectiles, Rockets,Missiles and guidance. 2013(6):86 88.

WANG Ru-ce, ect. Projectile end effect[M]. BeiJing: BeiJing institute of technology press, 1993.

ZHAO Wen-xuan, ect. terminal ballistics[M]. BeiJing: Weapon Industry Press, 1989. 